\title{
Batch-to-Batch Consistency of SB4 and SB2, Etanercept and Infliximab Biosimilars
}

\author{
Hans C. Ebbers ${ }^{1} \cdot$ Bjørn Fehrmann ${ }^{2} \cdot$ Mette Ottosen ${ }^{2} \cdot$ Niels Hvorslev $^{2} \cdot$ Pia Høier $^{2}$. Jae-Woong Hwang ${ }^{3}$. \\ Jinhan Chung ${ }^{3} \cdot$ Hyoung Taek Lim ${ }^{3} \cdot$ Shinjung Lee ${ }^{3} \cdot$ Juyoung Hong ${ }^{3} \cdot$ Mourad Farouk Rezk $^{1}$
}

Published online: 10 January 2020

(c) The Author(s) 2020

\begin{abstract} protein concentration, and biological activity. content of all batches of SB4. specifications defined by regulatory agencies.

\section{Key Points}

Biosimilars are held to the same rigorous quality standards as any other biologic.

SB4 and SB2 biosimilars demonstrated a high degree of batch-to-batch consistency.

Quality attributes including purity, percentage of high molecular weight species, tumor necrosis factor- $\alpha$ (TNF$\alpha$ ) binding, and TNF- $\alpha$ neutralization remained well within acceptance limits.
\end{abstract}

Background Biosimilars must meet stringent regulatory requirements, both at the time of authorization and during their lifecycle. Yet it has been suggested that divergence in quality attributes over time may lead to clinically meaningful differences between two versions of a biologic. Therefore, this study investigated the batch-to-batch consistency across a range of parameters for released batches of the etanercept biosimilar (SB4) and infliximab biosimilar (SB2).

Methods SB4 (Benepali ${ }^{\circledR}$ ) and SB2 (Flixabi ${ }^{\circledR}$ ) were both developed by Samsung Bioepis and are manufactured in Europe by Biogen at their facility in Hillerød, Denmark. A total of 120 batches of SB4 and 25 batches of SB2 were assessed for consistency and compliance with specified release parameters, including purity, post-translational glycosylation (SB4 only),

Results The protein concentration, purity, tumor necrosis factor- $\alpha$ (TNF- $\alpha$ ) binding, and TNF- $\alpha$ neutralization of all batches of SB4 and SB2 were within the strict specification limits set by regulatory agencies, as was the total sialic acid (TSA)

Conclusions Quality attributes of SB4 and SB2 batches showed little variation and were consistently within the rigorous

As of August 2019, the Biogen Hillerød facility (Denmark) became Fujifilm Diosynth Biotechnologies Denmark ApS, a contract development and manufacturing organization (CDMO) for the manufacture of biosimilars developed by Samsung Bioepis.

Electronic supplementary material The online version of this article (https://doi.org/10.1007/s40259-019-00402-0) contains supplementary material, which is available to authorized users.

Hans C. Ebbers

hans.ebbers@biogen.com

1 Biogen International GmbH, Neuhofstrasse 30, 6340 Baar, Switzerland

\section{Introduction}

A biosimilar medicine is defined by the European Medicines Agency as "a biological medicine that is highly similar to a biological medicine already marketed" and can be produced once the exclusivity period of the reference biologic has expired [1]. Regulatory agencies mandate that biosimilars have the same amino acid sequence as the reference protein, but variability in post-translational modifications is acceptable as long as these are not clinically relevant [2].

Although the uptake of biosimilars has increased considerably over recent years [3-5], some physicians have expressed concerns about the manufacturing process and quality [4]. Such concerns may be partly fuelled by reports of the potential for variability in the manufacturing process which might lead to divergence or 'drift' between biosimilars and the reference product. While this concern has been raised for biosimilars, drifting of quality attributes may also

2 Biogen (Denmark) Manufacturing APS, Hillerød, Denmark

Samsung Bioepis, Incheon, South Korea 
occur between reference products from different manufacturing facilities (whether it is a biosimilar or the branded biologic reference product) [6]. Differences in quality attributes have been observed for marketed products [2, 6-10]. In limited cases, changes in quality attributes have led to clinically relevant differences between different batches of the same product [11-12]. Recently this was shown for originator version of the monoclonal antibody trastuzumab (Herceptin ${ }^{\circledR}$ ), where a drift in the proportion of non-fucosylated glycans was associated with a reduced event-free survival (EFS) rate in patients receiving trastuzumab in the neo-adjuvant setting [12].

Because of the complexity of biologics and the inherent heterogeneity associated with their production, manufacturers of biosimilars need to provide a fullquality dossier demonstrating that a product can be manufactured consistently [13]. Not all quality attributes impact clinical efficacy or biological function, such as structure, biological and glycosylation profile, or process impurities [12]. Critical quality attributes (CQAs) are those attributes that need to be controlled to ensure the efficacy and safety of a product, and all CQAs need to be included in the active substance specifications. Specifications define the standards for ensuring consistent quality of a (biological) product throughout its lifecycle. They are agreed upon with regulatory authorities and include a large number of in-process controls and tests, as well as release criteria, so that no significant drifting of CQAs occurs over time, for example, following changes to its manufacturing process [11, 14-16]. By definition, a CQA is a physical, chemical, biological, or microbiological property or characteristic that should be within an appropriate limit, range, or distribution to ensure the desired product quality. CQAs are generally associated with raw materials (drug substance, excipients), intermediates (in-process materials), and drug product [17]. For biosimilars, these specifications may be stricter than those of the reference product $[11,18]$.

Samsung Bioepis has developed a range of biosimilars, including for the tumor necrosis factor- $\alpha$ (TNF- $\alpha$ ) inhibitors etanercept (SB4; Benepali ${ }^{\circledR}$ ) and infliximab (SB2; Flixabi ${ }^{\circledR}$ ), which are manufactured by Biogen (recently changed into Fujifilm Diosynth Biotechnologies Denmark ApS) at their manufacturing facility in Hillerød, Denmark. Before being released, each batch is tested to ensure it meets specifications outlined in the regulatory approval documents (Table 1). Here we report data on the batch-to-batch consistency of released batches of SB4 and SB2.

\section{Methods}

\subsection{Products}

One hundred and twenty batches of SB4 were released from the Hillerød facility between November 1, 2016 and
September 10, 2019, and 25 batches of SB2 were released between January 5, 2017 and August 31, 2018. Material from representative SB4 and SB2 batches obtained from commercial scale runs were used as reference standards throughout analytical testing.

\subsection{Size-Exclusion Chromatography}

Size-exclusion chromatography (SEC) was used to measure high molecular weight (HMW), low molecular weight (LMW), and monomer species, as described previously $[19,20]$. Samples of SB4 or SB2 were injected into a TSK-GEL G3000SW $\mathrm{Xl}_{\mathrm{Xl}}$ analytical column (Tosoh, $08541,5 \mu \mathrm{m} / 7.8 \mathrm{~mm} \times 300 \mathrm{~mm})$ at $25{ }^{\circ} \mathrm{C}$. The column was connected to a Waters high-performance liquid chromatography (HPLC) system (Waters Corporation; Milford, MA). For SB4, the mobile phase of the HPLC system used sodium phosphate $100 \mathrm{mmol} / \mathrm{L}$ and sodium chloride $200 \mathrm{mmol} / \mathrm{L}$ at a $\mathrm{pH}$ of 6.8 and a flow rate of $0.5 \mathrm{~mL} / \mathrm{min}$. For SB2, the mobile phase used sodium phosphate $100 \mathrm{mmol} / \mathrm{L}$ with $\mathrm{L}$-arginine monohydrochloride $500 \mathrm{mmol} / \mathrm{L}$ at a $\mathrm{pH}$ of 6.8 and a flow rate of $1.0 \mathrm{~mL} /$ min. Monomers and HMW species were detected using ultraviolet (UV) detection at a wavelength of $280 \mathrm{~nm}$. Data acquisition and processing were undertaken using Empower $^{\mathrm{TM}}$ (Waters) software or equivalent.

\subsection{Capillary Electrophoresis-Sodium Dodecyl Sulfate}

Purity was also assessed using a high-performance capillary electrophoresis-sodium dodecyl sulfate (CE-SDS) system [PA 800 plus Pharmaceutical Analysis System (Beckman Coulter; Brea, CA, USA)], as described previously $[19,20]$. The SB4 analysis was undertaken under reducing conditions, while the SB2 analysis used non-reducing conditions. In the reducing analysis, SB4 drug product sample was mixed with a $10-\mathrm{kDa}$ internal

Table 1 Release parameters for SB4 and SB2 assessed in this analysis

\begin{tabular}{lll}
\hline Parameter & SB4 stage & SB2 stage \\
\hline Protein concentration & Release & Release \\
Total sialic acid & Release & N/A \\
FRET binding assay & Release & Release \\
Reporter gene assay & Release & Release \\
High molecular weight by SEC & Release & Release \\
Total purity by CE-SDS & Release & Release \\
\hline
\end{tabular}

CE-SDS capillary electrophoresis-sodium dodecyl sulfate, FRET fluorescence resonance energy transfer, $N / A$ not assessed, SEC sizeexclusion chromatography 
standard, SDS-MW sample buffer (A10663, Beckman Coulter), and 2-mercaptoethanol (161-0710, Bio-Rad), and then heated in a water bath at $70{ }^{\circ} \mathrm{C}$ for $10 \mathrm{~min}$. Samples of SB2 drug product in the non-reducing analysis were mixed with a $10-\mathrm{kDa}$ internal standard, SDS-MW sample buffer (A10663, Beckman Coulter), and iodoacetamide. An electrode applied a voltage $(7.5 \mathrm{kV}$ in reducing conditions and $5 \mathrm{kV}$ in non-reducing conditions) to the sample for $20 \mathrm{~s}$ in order to transfer the sample electrokinetically onto a bare fused-silica capillary $(50 \mu \mathrm{m} / 30.2 \mathrm{~cm}$; Beckman Coulter), where it was separated. Electrophoresis was undertaken using $10 \mathrm{kV}$ and $15 \mathrm{kV}$ of separation voltage in reducing and non-reducing conditions, respectively. The system was monitored through the capillary window and aperture (Beckman Coulter, 144712, 100×200 $\mu \mathrm{m}$ ) by UV detection (wavelength of $220 \mathrm{~nm}$ ). Relevant data were collected by $32 \mathrm{Karat}^{\mathrm{TM}}$ software and processed by Empower ${ }^{\mathrm{TM}}$ software with integration capabilities.

\subsection{Quantitation of Total Sialic Acid}

Ion exclusion chromatography was used to measure the quantity of total sialic acids (TSAs), including $N$-acetylneuraminic acid (NANA) and $N$-glycolylneuraminic acid (NGNA), in each SB4 sample. The SB4 sample was hydrolyzed by adding $1 \mathrm{M}$ sulfuric acid (final sulfuric acid concentration of $0.1 \mathrm{~N}$ ). The sample was incubated at $80{ }^{\circ} \mathrm{C}$ for a minimum of $1 \mathrm{~h}$. Isocratic separation of NANA and NGNA was performed on a RHM-monosaccharide $\mathrm{H}(8 \%)$ column (Rezex ${ }^{\mathrm{TM}}(00 \mathrm{H}-01322-\mathrm{K} 0 / 300 \times 7.8 \mathrm{~mm}$ ); Phenomenex; Torrance, CA) and monitored with a UV detector (Shimadzu; Kyoto, Japan) at a wavelength of $206 \mathrm{~nm}$. Data collection and processing were via the Empower ${ }^{\mathrm{TM}}$ software with integration capabilities. NANA and NGNA contents were calculated from the calibration curves generated from data for NANA and NGNA standards and presented as the molar TSA amount per mole of polypeptide chain.

\subsection{Protein Concentration}

The protein concentration of SB2 and SB4 batches was determined in triplicate samples using an UV-visible spectrophotometer and a wavelength of $280 \mathrm{~nm}$. SB2 and SB4 batches were diluted into the target concentration using a volumetric flask. Each testing sample was prepared in triplicate. The concentration was calculated according to BeerLamberts law by multiplying the $280-\mathrm{nm}$ absorbance value by the dilution factor, and then dividing the product of this calculation by the extinction coefficient multiplied by the path length. The final concentration was determined by averaging triplicate measurements.

\subsection{TNF-a Binding Assay}

The TNF- $\alpha$ binding activity of SB4 and SB2 was determined using a time-resolved fluorescence resonance energy transfer (FRET) assay in accordance with previous reports [19, 20]. Thisassay uses Europium chelate-labeled etanercept or infliximab to compete with unlabeled SB4 or SB2, respectively, for binding to fluorophore Cy5-labeled TNF- $\alpha$. Briefly, the Europium chelate-labeled reference product and $\mathrm{Cy} 5$-labeled material were added to an assay plate at fixed concentrations and volumes. The plates were incubated for $1 \mathrm{~h}$ at ambient temperature while undergoing moderate agitation. The fluorescence signal, which is inversely proportional to TNF- $\alpha$ binding, was measured at a wavelength of $665 \mathrm{~nm}$ on a microplate reader (SpectraMax M5E (Molecular Devices; San Jose, CA, USA) or equivalent).

\subsection{TNF-a Neutralization Assay}

The inhibitory activity of SB4 and SB2 on the TNF- $\alpha$ signaling pathway was measured by a TNF- $\alpha$ neutralization assay that uses a luciferase reporter gene cell line [21]. In the luciferase reporter gene cells, the binding of TNF- $\alpha$ to its receptor triggers a signaling cascade that activates nuclear factor- $\mathrm{\kappa B}$, resulting in expression of the luciferase reporter gene. Therefore, when TNF- $\alpha$ receptor binding is inhibited (e.g., by SB4 or SB2), luciferase reporter gene expression is indirectly downregulated.

In the assay, TNF- $\alpha$ was mixed with samples of the assay standard, the biosimilar, or the reference biologic (etanercept or infliximab), and incubated in a 96-well tissue culture plate at ambient temperature for 30-120 min. Stable reporter cells were then added to each well of the tissue culture plate and the plates incubated for $24 \mathrm{~h}$, at which time luciferase activity was measured using the Steady-Glo ${ }^{\circledR}$ Luciferase Assay System (Promega Corporation; Madison, WI). The luminescence signal was read on a microplate reader (SpectraMax M5E (Molecular Devices; San Jose, CA, USA) or equivalent).

\subsection{Statistical Analysis}

Range, median, and interquartile range (IQR) were calculated for each parameter, using the SAS statistical software package (Cary, NC, USA).

\section{Results}

A total of 120 batches of SB4 (42 from 2016, 34 from 2017, 24 from 2018, and 20 from 2019) and 25 batches of SB2 (5 from 2015, 6 from 2017, and 14 from 2018) were included in the analysis (see Supplementary table 1 in Electronic Supplementary Material). 


\subsection{Purity}

The purity of SB4 and SB2, respectively, was based on the proportion of monomers present (excluding LMW and HMW species). The batch-to-batch consistency assessment confirmed that all measured batches of both agents met the specification criteria, with SB4 purity ranging from 96.8 to 98.2\% (median 97.6\% [IQR 97.4-97.8\%]; Fig. 1a) and SB2 purity ranging from $96.7 \%$ to $97.4 \%$ (median $97.1 \%$ [IQR 97.0-97.2\%]; Fig. 1b).

All batches of both SB4 and SB2 met specifications for HMW species content (Fig. 2a, b). HMW content of SB4 samples never exceeded $1.4 \%$ (range $0.5-1.4 \%$ ), with a median of $0.9 \%$ (IQR $0.8-1.0 \%$ ) across the measured batches. Of the 120 batches tested, 94 (78.3\%) contained $\leq 1.0 \%$ HMW species. SB2 batches consistently demonstrated low levels $(<1.0 \%)$ of HMW species (range $0.4-0.7 \%$; median $0.5 \%$ [IQR $0.5-0.5 \%$ ]).

\subsection{Sialic Acid Content}

The TSA content was consistently within specified parameters in the 120 tested batches of SB4 (Fig. 3). TSA content varied by $<2 \mathrm{~mol} / \mathrm{mol}$ chain across all batches, from a minimum of 14.7 to a maximum of 16.6 (median 16 [IQR 15.8-16.1]) $\mathrm{mol} / \mathrm{mol}$ chain.

\subsection{Protein Concentration}

The specified protein concentration for SB4 and SB2 were also maintained consistently across all batches. The range across all SB4 batches was 46.7 to $53.6 \mathrm{mg} / \mathrm{mL}$ (median 50.5 [IQR 49.8-51.3]; Fig. 4a). All SB2 batches were between 19.5 and $21.0 \mathrm{mg} / \mathrm{mL}$ (median 20.1 [IQR 19.8-20.4]; Fig. 4b).

\subsection{TNF-a Binding}

TNF- $\alpha$ receptor binding that was consistently within the specification limits for all released batches of SB4 (Fig. 5a) and SB2 (Fig. 5b). Across the 120 batches of SB4, TNF- $\alpha$ receptor binding ranged from 87 to $109 \%$ (median $98 \%$ [IQR 96-101\%]). For SB2 batches, TNF- $\alpha$ receptor binding ranged from 88 to $103 \%$ (median 98\% [IQR 97-99\%]).

\subsection{TNF-a Neutralization}

In the 120 tested batches of SB4, TNF- $\alpha$ neutralization was consistently within specified limits (range $82-118 \%$; Fig. 6a), as it was in the 25 tested batches of SB2 (range 85-109\%; Fig. 6b). Median TNF- $\alpha$ neutralization was $98 \%$ (IQR 94-101\%) with SB4 and 98\% (IQR 96-100\%) with SB2.
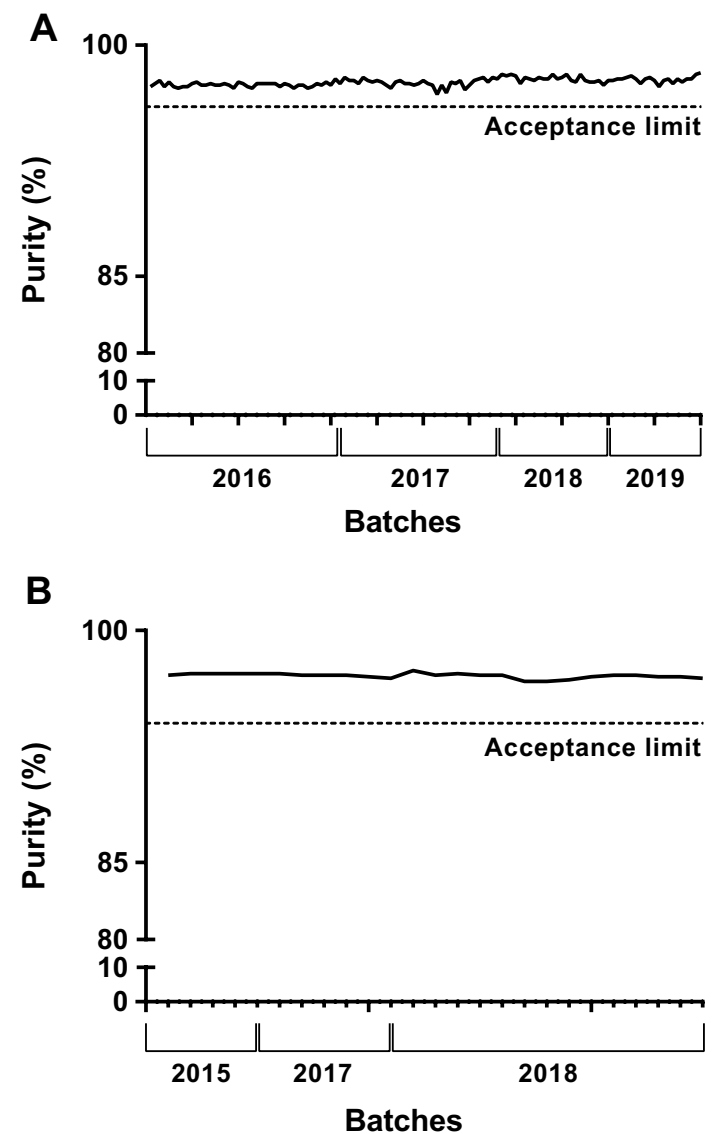

Fig. 1 Purity of each batch of a SB4 assessed by reduced capillary electrophoresis-sodium dodecyl sulfate (CE-SDS) analysis and b SB2 assessed by non-reduced CE-SDS analysis

\section{Discussion}

This study describes a high rate of consistency of CQAs between batches of SB4 and SB2 manufactured at the Biogen facility in Hillerød, Denmark using a panel of assays. Purity and the percentage of HMW species demonstrated a high degree of batch-to-batch consistency for SB4 and SB2, consistent with previous reports describing the HMW and LMW protein species present in SB4 compared with reference etanercept [19], and in SB2 compared with reference infliximab [20]. Functional assays of TNF- $\alpha$ binding (FRET binding assay) and TNF- $\alpha$ neutralization (reporter gene assay) also revealed similar and consistent functional characteristics between batches of SB4 and SB2 produced in Hillerød.

The purity of the biologic sample refers to the proportion of the content that consists of biologic monomers, excluding HMW species that represent protein aggregates and LMW species arising from protein fragmentation. The relative content of HMW species can affect the efficacy and immunogenicity of a biologic batch $[22,23]$. We demonstrated 
A

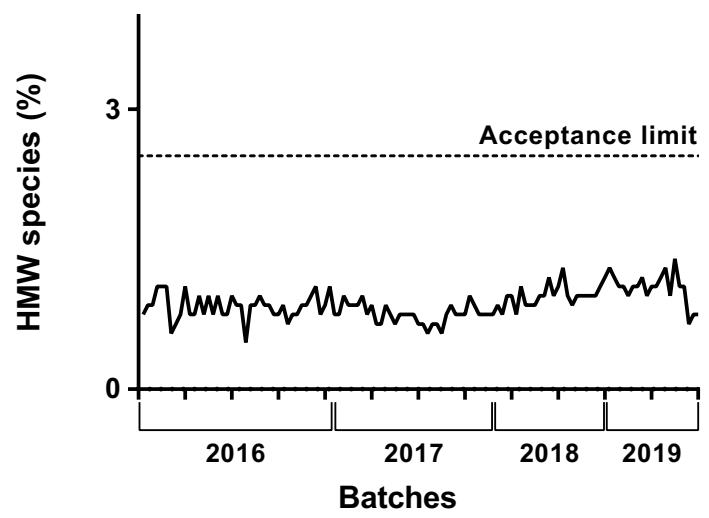

B

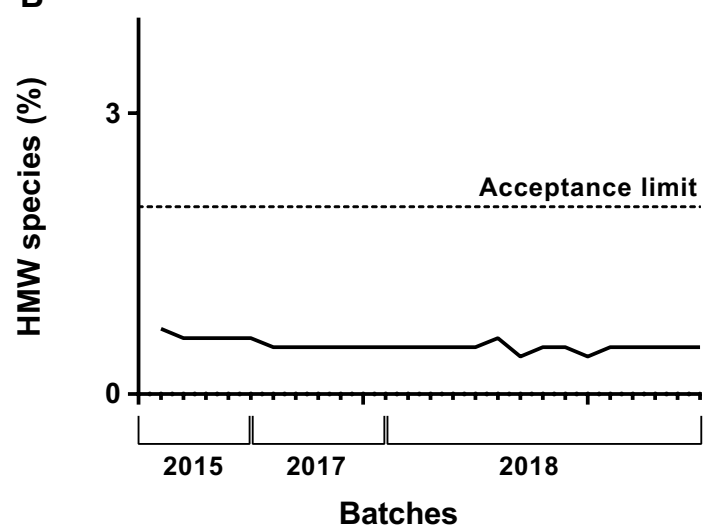

Fig. 2 High molecular weight (HMW) species present in a SB4 and b SB2 assessed by size-exclusion chromatography

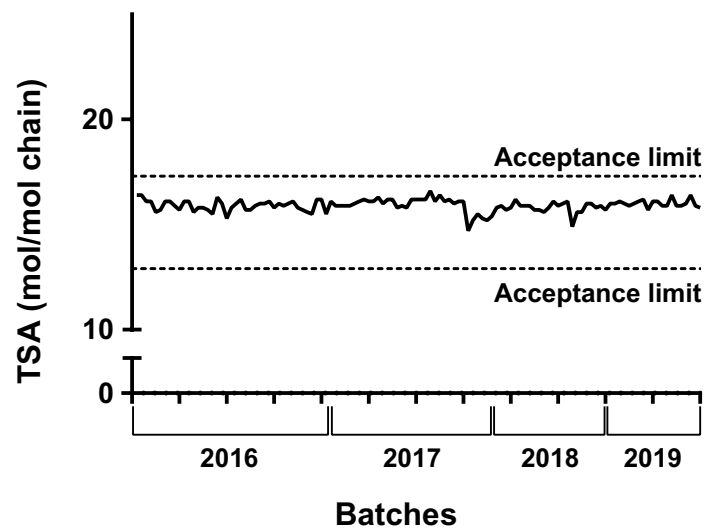

Fig. 3 Total sialic acid (TSA) content in batches of SB4

a median purity of $97.5 \%$ for SB4 batches and of $97.1 \%$ for SB2 batches. Levels of HMW species were well below the defined thresholds in the SB4 and SB2 specifications. Increased levels of HMW species may affect the efficacy and immunogenicity of a biologic $[22,23]$. The data presented
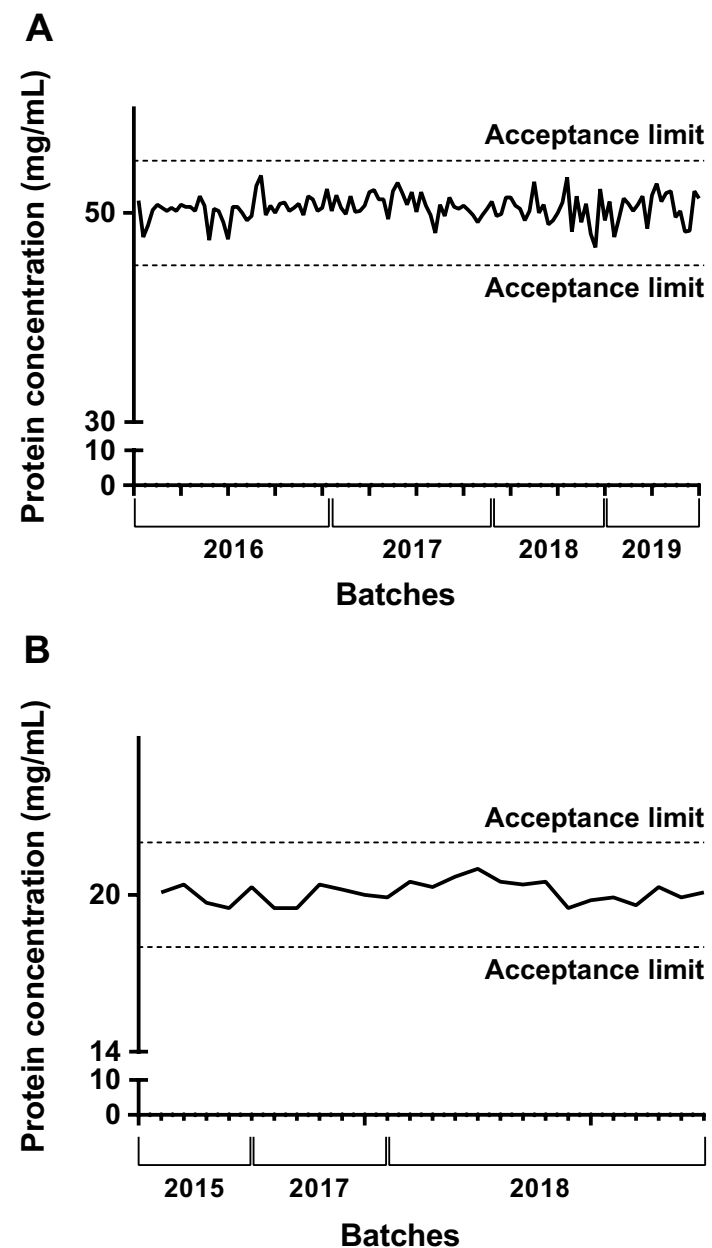

Fig. 4 Protein concentration of each batch of a SB4 and b SB2 assessed by absorbance (280-nm) spectrophotometry

here show a consistently low content of aggregates in batches of SB2 and SB4.

Glycosylation may play an important role in determining the stability, in vivo activity, solubility, serum halflife, andimmunogenicity of many recombinant therapeutic proteins [24, 25]. Our analysis showed that there was very little variation in TSA between batches of SB4. This is consistent with previous research showing that sialic acid content in separate samples of SB4 was similar; in addition, the TSA content of SB4 is almost identical to that of reference etanercept [19]. Across all batches, TSA content was within the specification limits defined for SB4, and varied by $<2 \mathrm{~mol} / \mathrm{mol}$ chain between batches. Moreover, the TSA content was consistent with that of reference etanercept, which contains up to $16 \mathrm{~mol} / \mathrm{mol}$ chain of sialic acid [19]. Reference etanercept includes 13 O-glycosylation sites (which are predominantly sialylated) and three $\mathrm{N}$-glycosylation sites [19]. $\mathrm{N}$-Glycans that may be present in biologics include mannose, galactose, fucose, NGNA, 

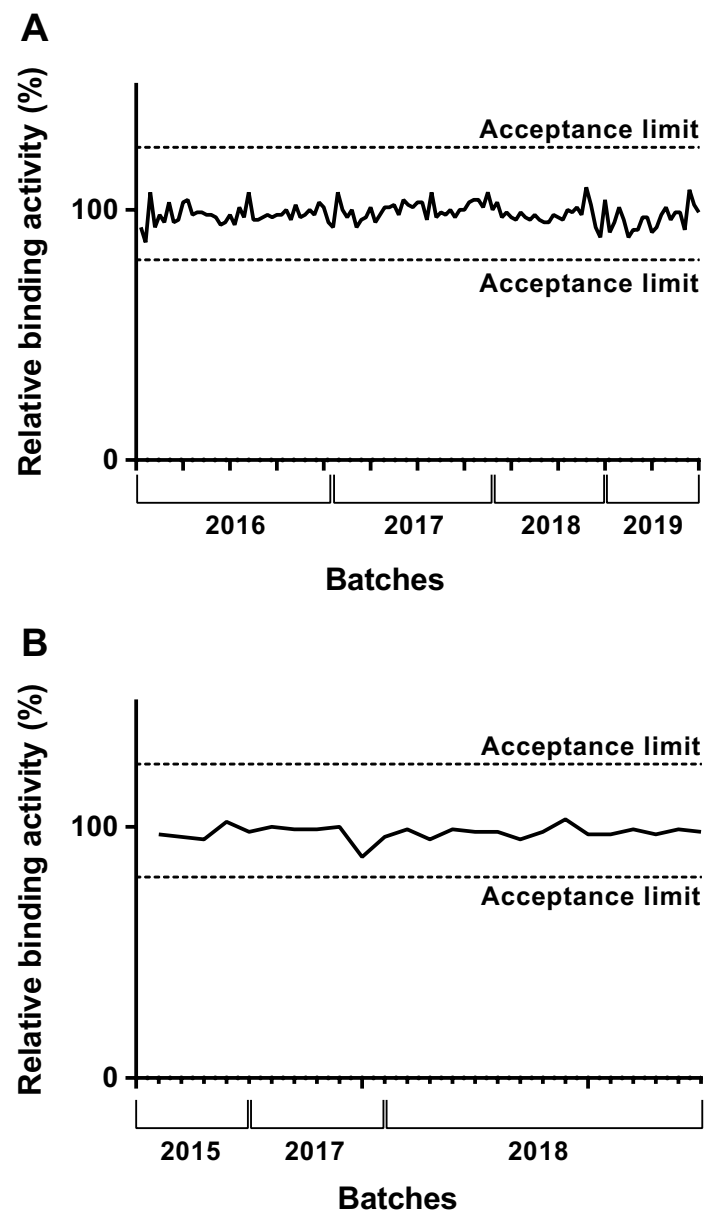

Fig. 5 Tumor necrosis factor- $\alpha$ (TNF- $\alpha$ ) binding of each batch of $\mathbf{a}$ SB4 and b SB2 assessed by fluorescence resonance energy transfer (FRET)

and NANA, the latter two of which are sialylated glycans $[14,25]$. The current analysis measured TSA in each batch sample, specifically the amount of NGNA and NANA present. NANA is the predominant sialic acid in SB4, accounting for $\geq 99.8 \%$ of the sialic acid present [19]. The low NGNA content of SB4 is a favorable attribute since NGNA is not synthesized by humans and is potentially immunogenic. The presence of NGNA in other biologics (e.g., cetuximab) has been linked to the development of antibodies and/or hypersensitivity reactions [26].

Etanercept and infliximab bind soluble (and transmembrane) TNF- $\alpha$, thereby preventing the activation of TNF receptors [27]. Therefore, the extent to which SB2 and SB4 bind TNF and inhibit TNF- $\alpha$ binding to the TNF receptor is the main determinant of the biological activity of these agents. All batches showed TNF- $\alpha$ binding within the specified limits for SB4 and SB2, with each agent showing a median relative binding activity of $98 \%$ across the tested batches. Similarly, TNF- $\alpha$ neutralization for both products was consistent with previous reports [19, 20].
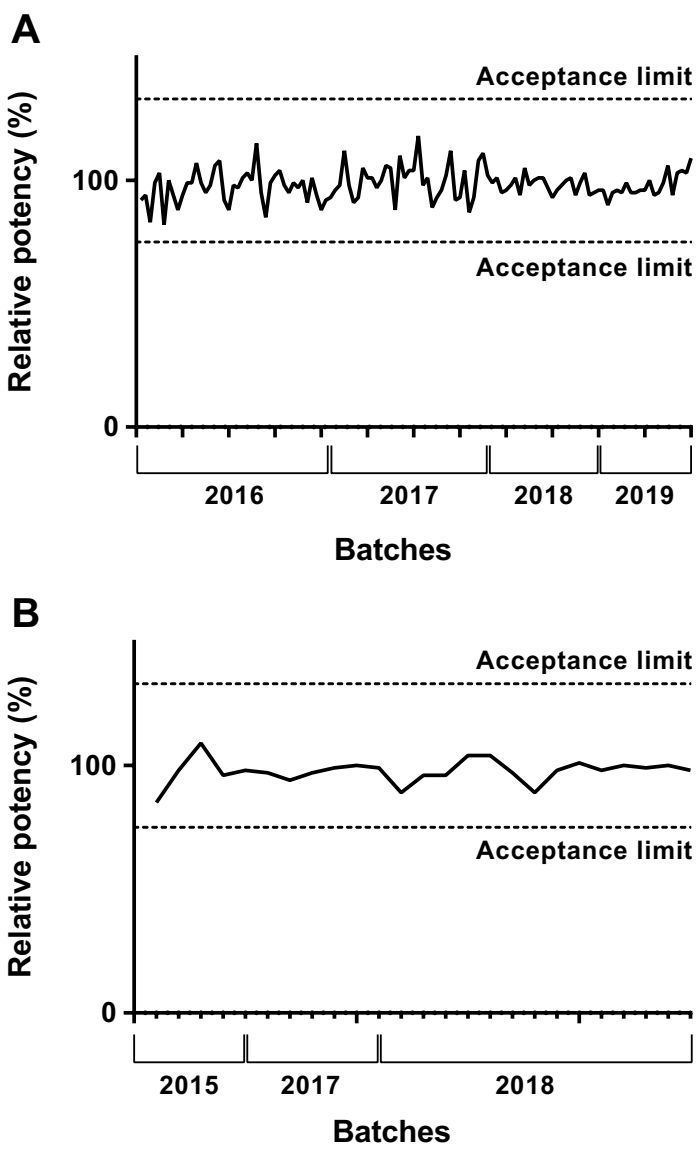

Fig. 6 Tumor necrosis factor- $\alpha$ (TNF- $\alpha)$ neutralization of each batch of a SB4 and b SB2 assessed by a luciferase reporter gene assay

While some degree of heterogeneity is unavoidable in biologic manufacturing, tight specifications for relevant quality attributes ensure that a product's benefit:risk profile is maintained throughout its lifecycle. Deviations in manufacturing consistency of any biological compound (biosimilar or reference product) have the potential to affect clinical efficacy and/or safety. Biosimilars are held to the same standards as reference products to ensure comparability of the product following manufacturing changes. Several changes have been introduced to the manufacturing process of SB2 and SB4 during the study period, but no quality drift in CQAs has been observed [28, 29]. There have been a number of examples of changes to quality attributes in the manufacture of reference biologic agents, including cetuximab (Erbitux $\left.{ }^{\circledR}\right)$, interferon- $\beta$-1a $\left(\right.$ Rebif $\left.^{\circledR}\right)$, and trastuzumab (Herceptin $^{\circledR}$ ) [11].

Variation in cetuximab manufacturing processes between sites in the USA and Europe led to differences in the pharmacokinetic properties of this biologic. Regulatory authorities noted that the pharmacokinetic exposure to cetuximab was $22 \%$ higher in patients receiving the product manufactured in Europe than it was in the patients receiving 
cetuximab manufactured in the USA $[11,30]$. The Food and Drug Administration (FDA) required the manufacturer to formally investigate any differences in efficacy or safety of cetuximab in clinical practice. Although this study did not show any clinically meaningful differences [31], the US prescribing information still reports the pharmacokinetic difference between cetuximab produced at the different manufacturing sites [30].

A cluster of cases of thrombotic microangiopathy were seen in patients being treated with interferon- $\beta-1 \mathrm{a}\left(\right.$ Rebif $\left.^{\circledR}\right)$ after the manufacturing process of this biologic was changed [32]. The formulation of interferon- $\beta-1 \mathrm{a}$ had been changed to remove bovine serum and human serum albumin, which were thought to contribute to neutralizing antibody development [11]. Although a causal relationship between the formulation change and the increase in thrombotic microangiopathy cases could not be proven, information on the potential development of this adverse event was added to the prescribing information for interferon- $\beta-1 \mathrm{a}\left(\operatorname{Rebif}^{\circledR}\right)$ [33].

The drift in product attributes of branded trastuzumab have been shown to affect the antibody-dependent cellmediated cytotoxicity (ADCC) of this agent [9], and patients who received the trastuzumab batches with lower ADCC had a lower rate of EFS compared with patients who did not receive these batches of trastuzumab. The 3-year EFS was $81.7 \%$ in patients who received trastuzumab with reduced ADCC, which was significantly lower than the $92.7 \%$ EFS rate in patients who received trastuzumab with unimpaired ADCC [12]. In patients who received the trastuzumab biosimilar SB3 (Ontruzant ${ }^{\circledR}$ ), the 3-year EFS was comparable to that in the group who received the trastuzumab batches without reduced ADCC [12]. Analytical testing of SB3 CQAs showed that SB3 was highly similar to the original (non-drifted) trastuzumab [12, 34].

These examples suggest that (1) product 'drift' is a concern in the manufacture of all biologics; (2) the 'drift' may create a divergence between biosimilar and originator; (3) such divergence may ultimately twist the comparative benefit-to-risk balance between both versions of the product; (4) changes in biologic product attributes can affect the efficacy of these agents; and (5) careful control of manufacturing and vigilant monitoring of CQAs is needed for all biologic products to demonstrate batch-to-batch consistency because CQAs are directly relevant to the product's benefit:risk profile. It is noteworthy that without biosimilar manufacturers monitoring batches of the reference drug, variation and drift in reference manufacture would likely never have been discovered. The trastuzumab example also indicates that the originator manufacturer's long-term knowledge of making a particular biologic is not in itself enough to prevent variation and drift. Biosimilar manufacturers may apply state-of-theart technologies and consider different release parameters, which may not have been monitored for a reference product.
SB4 and SB2 were approved based on a thorough demonstration of analytical, functional, and clinical similarity to the reference product [35-42]. The data presented here provide additional evidence that the quality of these products is consistent and maintained throughout their lifecycles. The data may provide additional reassurance for prescribers that these biosimilars are high-quality products that meet stringent quality criteria.

This study is not without limitations. First, a limited number of batches of SB2 were available for analysis. Second, the CQAs monitored during quality assurance during their lifecycle do not include all of the parameters that are described in the regulatory dossier to establish biosimilarity. Finally, the current study was limited to an analysis of the quality attributes that were obtained for SB2 and SB4; to truly exclude drifting of quality attributes between different products, a comparison with the reference product would be required, which was beyond the scope of the current study.

\section{Conclusions}

The manufacture of SB4 and SB2 is stable and robust and produces biosimilars that are consistently within the rigorous specifications defined in the regulatory approval dossier, and no evidence for drifting of quality attributes was observed. The data presented here should add to the overall confidence of physicians and patients that SB4 and SB2 are of a consistently high quality and are manufactured according to the highest, state-of-the-art standards.

Acknowledgements We would like to thank Catherine Rees of Springer Healthcare Communications who wrote the outline of this manuscript. This medical writing assistance was funded byBiogen.

\section{Compliance with Ethical Standards}

Funding This article was funded by Biogen.

Conflict of interest Hans Ebbers, Bjørn Fehrmann, Mette Ottosen, Niels Hvorslev, and Pia Høier are employed by Biogen and may hold stock in Biogen. Mourad Farouk Rezk is employed by and holds stock in Biogen. Biogen is responsible for the commercialization of SB4 and SB2. Jae-Woong Hwang, Shinjung Lee, Jinhan Chung, Juyoung Hong, and Hyoung Taek Lim are employed by Samsung Bioepis and hold stock in Samsung Bioepis.

Open Access This article is licensed under a Creative Commons Attribution-NonCommercial 4.0 International License, which permits any non-commercial use, sharing, adaptation, distribution and reproduction in any medium or format, as long as you give appropriate credit to the original author(s) and the source, provide a link to the Creative Commons licence, and indicate if changes were made. The images or other third party material in this article are included in the article's Creative Commons licence, unless indicated otherwise in a credit line to the 
material. If material is not included in the article's Creative Commons licence and your intended use is not permitted by statutory regulation or exceeds the permitted use, you will need to obtain permission directly from the copyright holder.To view a copy of this licence, visit http://creativecommons.org/licenses/by-nc/4.0/.

\section{References}

1. European Medicines Agency. Biosimilars in the EU: information guide for healthcare professionals, London; 2017. https://www. ema.europa.eu/en/documents/leaflet/biosimilars-eu-informatio n-guide-healthcare-professionals_en.pdf.

2. Schiestl M, Stangler T, Torella C, Cepeljnik T, Toll H, Grau R. Acceptable changes in quality attributes of glycosylated biopharmaceuticals. Nat Biotechnol. 2011;29(4):310-2. https://doi. org/10.1038/nbt.1839.

3. Aladul MI, Fitzpatrick RW, Chapman SR. Healthcare professionals' perceptions and perspectives on biosimilar medicines and the barriers and facilitators to their prescribing in UK: a qualitative study. BMJ Open. 2018;8(11):e023603. https://doi.org/10.1136/ bmjopen-2018-023603.

4. Beck M, Michel B, Rybarczyk-Vigouret MC, Leveque D, Sordet C, Sibilia J, et al. Rheumatologists' perceptions of biosimilar medicines prescription: findings from a French web-based survey. BioDrugs. 2016;30(6):585-92. https://doi.org/10.1007/s4025 9-016-0202-5.

5. Scherlinger M, Langlois E, Germain V, Schaeverbeke T. Acceptance rate and sociological factors involved in the switch from originator to biosimilar etanercept (SB4). Semin Arthritis Rheum. 2019;48(5):927-32. https://doi.org/10.1016/j.semarthrit .2018.07.005.

6. Ramanan S, Grampp G. Drift, evolution, and divergence in biologics and biosimilars manufacturing. BioDrugs. 2014;28(4):363-72. https://doi.org/10.1007/s40259-014-0088-z.

7. Halim LA, Brinks V, Jiskoot W, Romeijn S, Haselberg R, Burns $\mathrm{C}$, et al. Quality and batch-to-batch consistency of original and biosimilar epoetin products. J Pharm Sci. 2016;105(2):542-50. https://doi.org/10.1016/j.xphs.2015.10.019.

8. Hassett B, Scheinberg M, Castaneda-Hernandez G, Li M, Rao URK, Singh E, et al. Variability of intended copies for etanercept $(\operatorname{Enbrel}(\mathrm{R}))$ : data on multiple batches of seven products. MAbs. 2018;10(1):166-76.https://doi.org/10.1080/19420862.2017.13873 46.

9. Kim S, Song J, Park S, Ham S, Paek K, Kang M, et al. Drifts in ADCC-related quality attributes of Herceptin(R): impact on development of a trastuzumab biosimilar. MAbs. 2017;9(4):704-14. https://doi.org/10.1080/19420862.2017.1305530.

10. Tu CL, Wang YL, Hu TM, Hsu LF. Analysis of pharmacokinetic and pharmacodynamic parameters in EU- versus US-licensed reference biological products: are in vivo bridging studies justified for biosimilar development? BioDrugs. 2019. https://doi. org/10.1007/s40259-019-00357-2.

11. Lamanna WC, Holzmann J, Cohen HP, Guo X, Schweigler M, Stangler T, et al. Maintaining consistent quality and clinical performance of biopharmaceuticals. Expert Opin Biol Ther. 2018;18(4):369-79. https://doi.org/10.1080/14712 598.2018.1421169.

12. Pivot X, Pegram M, Cortes J, Luftner D, Lyman GH, Curigliano $\mathrm{G}$, et al. Three-year follow-up from a phase 3 study of SB3 (a trastuzumab biosimilar) versus reference trastuzumab in the neoadjuvant setting for human epidermal growth factor receptor 2-positive breast cancer. Eur J Cancer. 2019;120:1-9. https:// doi.org/10.1016/j.ejca.2019.07.015.
13. International Conference on Harmonisation of Technical Requirements for Registration of Pharmaceuticals for Human Use. Specifications: test procedures and acceptance criteria for biotechnological/biological products 1999 Contract No.: Q6B.

14. Vulto AG, Jaquez OA. The process defines the product: what really matters in biosimilar design and production? Rheumatology (Oxford). 2017;56(suppl 4):iv14-29. https://doi. org/10.1093/rheumatology/kex278.

15. Goel N, Chance K. Biosimilars in rheumatology: understanding the rigor of their development. Rheumatology (Oxford). 2017;56(2):187-97. https://doi.org/10.1093/rheumatology/ kew206.

16. Kirchhoff CF, Wang XM, Conlon HD, Anderson S, Ryan AM, Bose A. Biosimilars: key regulatory considerations and similarity assessment tools. Biotechnol Bioeng. 2017;114(12):2696705. https://doi.org/10.1002/bit.26438.

17. European Medicines Agency. ICH Topic Q 8 (R2) Pharmaceutical Development; 2009. https://www.ema.europa.eu/en/docum ents/scientific-guideline/note-guidance-pharmaceutical-devel opment_en.pdf. Accessed 10 Dec 2019.

18. Geigert J. The challenge of CMC regulatory compliance for biopharmaceuticals. 3rd ed. Cham: Springer; 2019.

19. Cho IH, Lee N, Song D, Jung SY, Bou-Assaf G, Sosic Z, et al. Evaluation of the structural, physicochemical, and biological characteristics of SB4, a biosimilar of etanercept. MAbs. 2016;8(6):1136-55. https://doi.org/10.1080/19420 862.2016.1193659.

20. Hong J, Lee Y, Lee C, Eo S, Kim S, Lee N, et al. Physicochemical and biological characterization of SB2, a biosimilar of Remicade(R) (infliximab). MAbs. 2017;9(2):364-82. https ://doi.org/10.1080/19420862.2016.1264550.

21. Lallemand C, Kavrochorianou N, Steenholdt C, Bendtzen K, Ainsworth MA, Meritet JF, et al. Reporter gene assay for the quantification of the activity and neutralizing antibody response to TNFalpha antagonists. J Immunol Methods. 2011;373(12):229-39. https://doi.org/10.1016/j.jim.2011.08.022.

22. Rosenberg AS. Effects of protein aggregates: an immunologic perspective. Aaps J. 2006;8(3):E501-7. https://doi.org/10.1208/ aapsj080359.

23. Moussa EM, Panchal JP, Moorthy BS, Blum JS, Joubert MK, Narhi LO, et al. Immunogenicity of therapeutic protein aggregates. J Pharm Sci. 2016;105(2):417-30. https://doi. org/10.1016/j.xphs.2015.11.002.

24. Zhou Q, Qiu H. The Mechanistic impact of N-glycosylation on stability, pharmacokinetics, and immunogenicity of therapeutic proteins. J Pharm Sci. 2019;108(4):1366-77. https://doi. org/10.1016/j.xphs.2018.11.029.

25. Higel F, Seidl A, Sorgel F, Friess W. N-glycosylation heterogeneity and the influence on structure, function and pharmacokinetics of monoclonal antibodies and $\mathrm{Fc}$ fusion proteins. Eur $\mathrm{J}$ Pharm Biopharm. 2016;100:94-100. https://doi.org/10.1016/j. ejpb.2016.01.005.

26. van Beers MM, Bardor M. Minimizing immunogenicity of biopharmaceuticals by controlling critical quality attributes of proteins. Biotechnol J. 2012;7(12):1473-84. https://doi. org/10.1002/biot.201200065.

27. Tracey D, Klareskog L, Sasso EH, Salfeld JG, Tak PP. Tumor necrosis factor antagonist mechanisms of action: a comprehensive review. Pharmacol Ther.2008;117(2):244-79.

28. European Medicines Agency. Benepali; 2019. https://www.ema. europa.eu/en/documents/procedural-steps-after/benepali-eparprocedural-steps-taken-scientific-information-after-authorisat ion_en.pdf. Accessed 9 Dec 2019.

29. European Medicines Agency. Flixabi; 2019. https://www.ema. europa.eu/en/documents/procedural-steps-after/flixabi-epar-proce 
dural-steps-taken-scientific-information-after-authorisation en.pdf. Accessed 9 Dec 2019.

30. Food and Drug Administration. Erbitux ${ }^{\circledR}$ (cetuximab) injection, for intravenous use. Prescribing information; 2019. https://www. accessdata.fda.gov/drugsatfda_docs/label/2019/125084s273lbl. pdf.

31. Soulieres D, Aguilar JL, Chen E, Misiukiewicz K, Ernst S, Lee $\mathrm{HJ}$, et al. Cetuximab plus platinum-based chemotherapy in head and neck squamous cell carcinoma: a randomized, double-blind safety study comparing cetuximab produced from two manufacturing processes using the EXTREME study regimen. BMC Cancer. 2016;16:19. https://doi.org/10.1186/s12885-016-2064-0.

32. Hunt D, Kavanagh D, Drummond I, Weller B, Bellamy C, Overell J, et al. Thrombotic microangiopathy associated with interferon beta. N Engl J Med. 2014;370(13):1270-1. https://doi. org/10.1056/NEJMc1316118.

33. Food and Drug Administration. REBIF (interferon beta-1a), for subcutaneous injection. Prescribing information; 2019. https:// www.accessdata.fda.gov/drugsatfda_docs/label/2019/103780s520 4lbl.pdf.

34. Lee JH, Paek K, Moon JH, Ham S, Song J, Kim S. Biological characterization of SB3, a trastuzumab biosimilar, and the influence of changes in reference product characteristics on the similarity assessment. BioDrugs. 2019;33(4):411-22. https://doi. org/10.1007/s40259-019-00362-5.

35. Choe JY, Prodanovic N, Niebrzydowski J, Staykov I, Dokoupilova E, Baranauskaite A, et al. A randomised, double-blind, phase III study comparing SB2, an infliximab biosimilar, to the infliximab reference product Remicade in patients with moderate to severe rheumatoid arthritis despite methotrexate therapy. Ann Rheum Dis. 2017;76(1):58-64. https://doi.org/10.1136/annrheumdi s-2015-207764.

36. Emery P, Vencovsky J, Sylwestrzak A, Leszczynski P, Porawska W, Baranauskaite A, et al. A phase III randomised, doubleblind, parallel-group study comparing SB4 with etanercept reference product in patients with active rheumatoid arthritis despite methotrexate therapy. Ann Rheum Dis. 2017;76(1):51-7. https:// doi.org/10.1136/annrheumdis-2015-207588.

37. Emery P, Vencovsky J, Sylwestrzak A, Leszczynski P, Porawska W, Baranauskaite A, et al. 52-week results of the phase 3 randomized study comparing SB4 with reference etanercept in patients with active rheumatoid arthritis. Rheumatology (Oxford). 2017;56(12):2093-101. https://doi.org/10.1093/rheumatology/ kex269.

38. Emery P, Vencovsky J, Sylwestrzak A, Leszczynski P, Porawska W, Stasiuk B, et al. Long-term efficacy and safety in patients with rheumatoid arthritis continuing on SB4 or switching from reference etanercept to SB4. Ann Rheum Dis. 2017. https://doi. org/10.1136/annrheumdis-2017-211591.

39. Girolomoni G, Feldman SR, Emery P, Ghil J, Keum JW, Cheong $\mathrm{SY}$, et al. Comparison of injection-site reactions between the etanercept biosimilar SB4 and the reference etanercept in patients with rheumatoid arthritis from a phase III study. Br J Dermatol. 2018;178(3):e215-6. https://doi.org/10.1111/bjd.16032.

40. Lee YJ, Shin D, Kim Y, Kang J, Gauliard A, Fuhr R. A randomized phase 1 pharmacokinetic study comparing SB4 and etanercept reference product $(\operatorname{Enbrel}(\mathrm{R}))$ in healthy subjects. Br J Clin Pharmacol. 2016;82(1):64-73. https://doi.org/10.1111/bcp.12929.

41. Smolen JS, Choe JY, Prodanovic N, Niebrzydowski J, Staykov I, Dokoupilova E, et al. Comparing biosimilar SB2 with reference infliximab after 54 weeks of a double-blind trial: clinical, structural and safety results. Rheumatology (Oxford). 2017;56(10):1771-9. https://doi.org/10.1093/rheumatology/kex25 4.

42. Smolen JS, Choe JY, Prodanovic N, Niebrzydowski J, Staykov I, Dokoupilova E, et al. Safety, immunogenicity and efficacy after switching from reference infliximab to biosimilar SB2 compared with continuing reference infliximab and SB2 in patients with rheumatoid arthritis: results of a randomised, double-blind, phase III transition study. Ann Rheum Dis. 2018;77(2):234-40. https:// doi.org/10.1136/annrheumdis-2017-211741. 